\title{
Infection and cox2 sequence of Pythium chondricola (Oomycetes) causing red rot disease in Pyropia yezoensis (Rhodophyta) in Korea
}

\author{
Soon Jeong Lee ${ }^{1}$, Bo Young Jee ${ }^{2}$, Maeng-Hyun Son ${ }^{2}$ and Sang-Rae Lee ${ }^{3, *}$ \\ ${ }^{1}$ Seaweed Research Center, National Institute of Fisheries Science, Mokpo 58746, Korea \\ ${ }^{2}$ Aquatic Life Disease Control Division, National Institute of Fisheries Science, Busan 46083, Korea \\ ${ }^{3}$ Marine Research Institute, Pusan National University, Busan 46241, Korea
}

Red rot disease has caused a major decline in Pyropia (Nori) crop production in Korea, Japan, and China. To date, only Pythium porphyrae (Pythiales, Oomycetes) has been reported as the pathogen causing red rot disease in Pyropia yezoensis (Rhodophyta, Bangiales). Recently, Pythium chondricola was isolated from the infected blades of Py. yezoensis during molecular analyses using the mitochondrial coxl region. In this study, we evaluated the pathogenicity of $P$. chondricola as an algal pathogen of Py. yezoensis. Moreover, a new cox2 marker was developed with high specificity for Pythium species. Subsequent to re-inoculation, P. chondricola successfully infected $P y$. yezoensis blades, with the infected regions containing symptoms of red rot disease. A novel cox2 marker successfully isolated the cox 2 region of Pythium species from the infected blades of Py. yezoensis collected from Pyropia aquaculture farms. cox 2 sequences showed $100 \%$ identity with that of P. chondricola (KJ595354) and 98\% similarity with that of P. porphyrae (KJ595377). The results of the pathogenicity test and molecular analysis confirm that $P$. chondricola is a new algal pathogen causing red rot disease in Pyropia species. Moreover, it could also suggest the presence of cryptic biodiversity among Korean Pythium species.

Key Words: cox2; Koch’s postulates; Pathogenesis; Pyropia yezoensis; Pythium chondricola; red rot disease

\section{INTRODUCTION}

Red rot disease was first reported on Pyropia tenera in Japan (Arasaki 1947), and its pathogenesis has been characterized in Pyropia species (Takahashi et al. 1977). Outbreaks of red rot disease on Pyropia species have caused major damage to commercial Pyropia aquaculture systems in Korea, Japan, and China (Kawamura et al. 2005, Blouin et al. 2011, Kim et al. 2014).

After the first report of red rot disease on Pyropia tenera, only Pythium porphyrae (Pythiales, Oomycetes) was identified as a pathogen of red rot disease in Pyropia species in Korea, Japan, and China (Park et al. 2006, Liu et al. 2012, Kim et al. 2014). Recently, we isolated Pythium chondricola from the infected blades of Pyropia yezoensis collected from commercial Pyropia aquaculture farms based on the mitochondrial coxl region (Lee et al. 2015).

Using coxl markers, $P$. chondricola was detected in $P y$. yezoensis, and was confirmed to be genetically different from the P. porphyrae detected in Japan. This was the first report of the presence of P. chondricola on Pyropia species, following the first taxonomic report of its occurrence on the red alga Chondrus crispus (De Cock 1986). However, the pathogenesis of $P$. chondricola must be proven
(9) \$ This is an Open Access article distributed under the terms of the Creative Commons Attribution Non-Commercial License (http://creativecommons.org/licenses/by-nc/3.0/) which permits unrestricted non-commercial use, distribution, and reproduction in any medium, provided the original work is properly cited.
Received April 2, 2017, Accepted May 16, 2017

*Corresponding Author

E-mail: oceanoalgae@naver.com

Tel: +82-51-510-3368, Fax: +82-51-581-2963 
to confirm that it is an algal pathogen causing red rot disease in Pyropia species (i.e., proven to satisfy Koch's postulates).

For precise identification of oomycete species, it is necessary to develop multiple molecular markers (Lévesque and De Cock 2004, Seifert 2009, Robideau et al. 2011). In this regard, Choi et al. (2015) recently compared the efficiency of using the pattern of sequence variation between $\operatorname{cox} 2$ and cox 1 regions for species identification. They accordingly found that cox2 showed higher interspecific and lower intraspecific divergence than coxl, and was more successful in species identification. Therefore, the cox2 region has been suggested as a successful partner DNA barcode marker.

Following the detection of $P$. chondricola in an infected blade of Py. yezoensis using the coxl region (Lee et al. 2015), a new cox2 gene sequence (KJ595354) of P. chondricola was published in GenBank (National Center for Biotechnology Information, NCBI). Therefore, we developed a new primer set to amplify the cox2 region that also exhibits specificity for Pythium species. A molecular examination was conducted based on the Pythium-specific cox2 gene marker developed in this study. Pythium cox2 sequences were isolated from the infected blades of $P y$. yezoensis with red rot disease, and were compared with cox2 sequences in GenBank. We also conducted a re-inoculation test to satisfy Koch's postulates using an isolate from the infected Py. yezoensis. These analyses were expected to confirm the pathogenesis of $P$. chondricola on Py. yezoensis.

\section{MATERIALS AND METHODS}

\section{Sample preparation}

We used Pythium-infected blades of Py. yezoensis collected from aquaculture farms in Korea (Biando [Gunsan] and Aphaedo [Shinan] in December 2014). Pyropia samples with signs of red rot disease were also collected from Gaeyado (Dec 2014, Gunsan, Korea). The presence of $P$. chondricola was confirmed in these Pyropia samples (Lee et al. 2015). Strains of $P$. chondricola were isolated from $P y$. yezoensis collected from Biando and Aphaedo (Dec 2014, Korea) and were cultured in the Seaweed Research Center (National Institute of Fisheries Science, Mokpo, Korea). In addition, a culture strain of $P$. chondricola (Biando, Korea; NIFS-PC-001) has been deposited in the Marine BioRe- sources Bank (MBRB) in the Seoul National University, Korea (SFC20170403-M01). Species identification of the cultured strain was conducted using the coxl marker (Lee et al. 2015).

\section{Re-inoculation experiment}

We inoculated the P. chondricola strain onto cornmeal agar and Arasaki B medium (Arasaki et al. 1968), and maintained the culture (Biando) at $15^{\circ} \mathrm{C}$. A re-inoculation test was performed in accordance with Koch's postulates. Blades of Py. yezoensis used in the re-inoculation test were cultured at $15^{\circ} \mathrm{C}$ under white fluorescent irradiation of approximately $20 \mu \mathrm{mol}$ photons $\mathrm{m}^{-2} \mathrm{~s}^{-1}$ and a 12 : 12-h light : dark cycle. Morphological observations during the infection of $P$. chondricola on the healthy blade of $P y$. yezoensis were conducted using a microscope (Nikon Eclipse Ni-u, Tokyo, Japan) (Fig. 1).

\section{Development of a Pythium-specific cox 2 marker and molecular analyses}

We developed a new primer set to amplify the cox2 region of $P$. chondricola. For primer design, we compared two cox2 gene sequences of $P$. chondricola (KJ595354) and P. porphyrae (KJ595377) from GenBank. We initially searched the conserved regions of the two species. We excluded the cox 2 region conserved among other oomycetes, except for Pythium species.

Because these two species have a close taxonomic relationship (Lévesque and De Cock 2004), a new cox2 marker was designed for putative specificity in P. chondricola, $P$. porphyrae, and $P$. adhaerens. To evaluate the specificity of the newly developed cox 2 primers for Pythium species, we compared their specificity against that of previously reported cox2 primer pairs (COX2F/COX2R, FM66/FM58) (Hudspeth et al. 2000, Villa et al. 2006, Senda et al. 2009, Choi et al. 2015).

DNA extraction, polymerase chain reaction (PCR) amplification, and sequencing processes followed the methods described by Lee et al. (2015). Total DNAs were extracted from a culture strain of $P$. chondricola and the infected field samples of $P$ y. yezoensis. The putative infection of P. chondricola in Pyropia samples was investigated using the cox 1 marker (Lee et al. 2015). Similarity analysis was conducted using the BLAST searching tool in GenBank. 

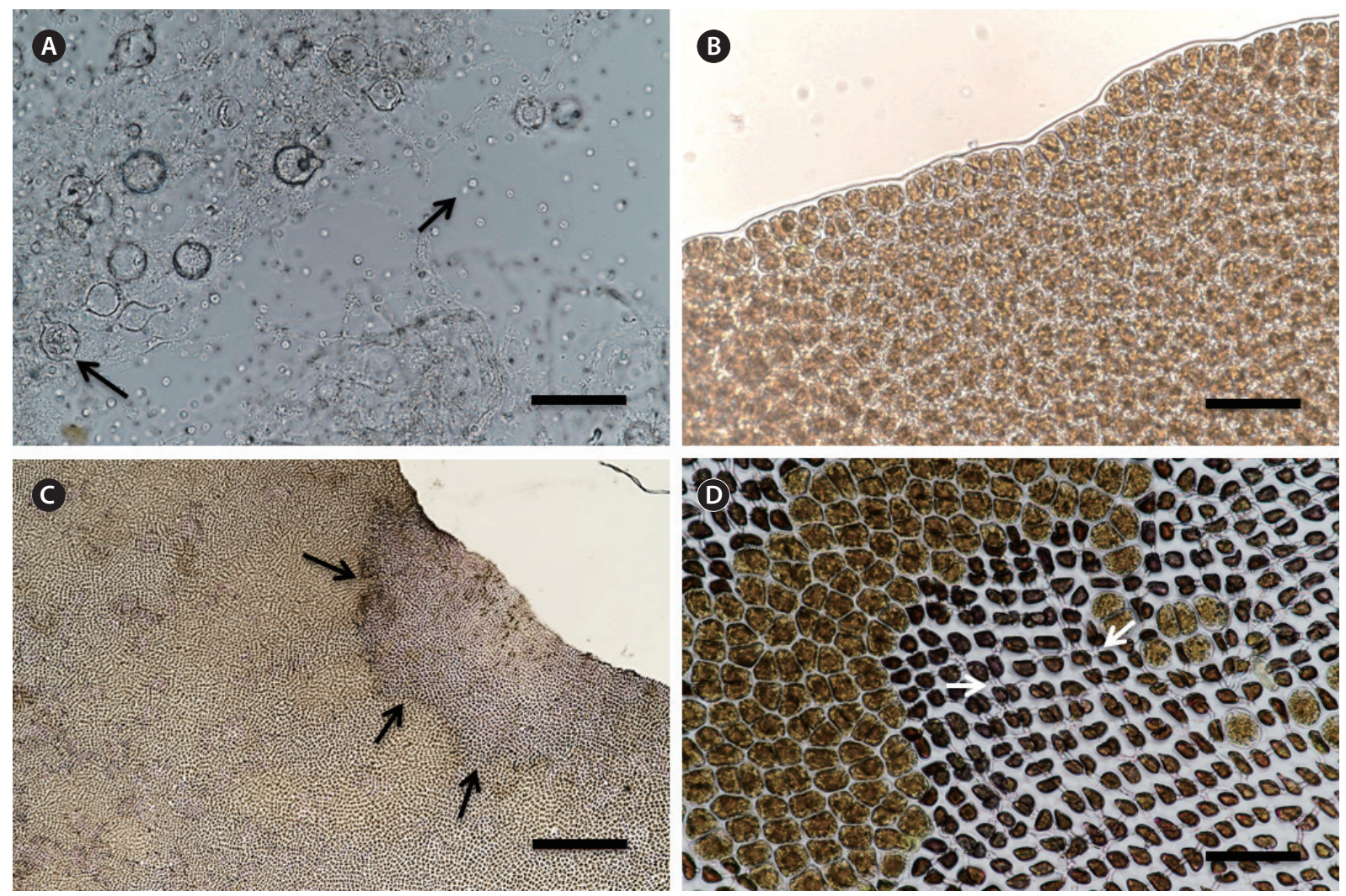

Fig. 1. (A) Zoosporangium formation and zoospore release (arrows) of the Pythium chondricola culture strain isolated from an infected blade of Pyropia yezoensis. (B) A healthy blade of Py. yezoensis. (C) Py. yezoensis 2 days after artificial infection with the released zoospores of $P$. chondricola. Pyropia yezoensis cells showed symptoms of red rot disease. The lesioned area lost its original color and developed a purple and greenish color (arrows). (D) Mycelia of $P$. chondricola formed over the lesioned area (arrows). Scale bars represent: A, B \& D, $50 \mu \mathrm{m} ; C, 500 \mu \mathrm{m}$.

\section{RESULTS}

\section{Infection of Pyropia yezoensis by Pythium chon- dricola}

The morphological features of Py. yezoensis blades were observed during infection by P. chondricola. The formation of a zoosporangium and the release of zoospores were accordingly observed (Fig. 1A). Two days after reinoculation, Pyropia cells in the blade showed symptoms of red rot disease. The area of the lesion in the infected blade lost its original color and developed a purple and greenish color (Fig. 1C). P. chondricola mycelia were also observed in the lesioned area (Fig. 1D).

\section{Pythium-specific cox 2 marker development for the detection of Pythium chondricola}

In this study, we developed the following primer pair: forward primer, cox2-PACP-F1 (5'-GATGTTATTTA-
AAACAATAGTTC-3'); and reverse primer, cox2-PACP-R1 (5'-TAAAGAAGGAATAGCCCAA-3'). PCR was successfully conducted on the infected blades of Py. yezoensis using this new primer pair. We also acquired PCR products from the culture strain. The COX2F/COX2R and FM66/FM58 primer pairs used in previous studies showed amplicons of different sizes, approximately $600 \mathrm{bp}$.

From sequencing, we successfully isolated the cox2 region using our newly developed primer pair (cox2PACP-F1/cox2-PACP-R1). The cox 2 sequences isolated from culture strains of $P$. chondricola and the infected host blades of Py. yezoensis (Biando and Aphaedo) have an identical sequence (GenBank accession number KU754146 [373 bp]). With the exception of the primer binding sites, the cox 2 regions showed $100 \%$ similarity (373/373) with that P. chondricola (KJ595354; CBS:203.85, The Netherlands), 98\% (367/373) with that of P. porphyrae (KJ595377; CBS:369.79, Japan), and 97\% (362/373) with that of P. adhaerens (KJ595386; CBS:520.74, The Netherlands). The coxl sequences of these three Pythium strains 
(CBS:203.85, CBS:369.79, CBS:520.74) were also found in GenBank, and these sequences were analyzed by Lee et al. (2015). We have deposited the $\operatorname{cox} 1$ sequences of $P$. chondricola reported by Lee et al. (2015). All Korean samples have an identical cox 1 sequence (GenBank accession number KY124355, 386 bp). Whereas the interspecific sequence variations identified using the cox 1 region were consistent, the cox 2 marker showed more variable sequences.

The primers used in previous cox 2 studies could not amplify the cox 2 region of Pythium species. The primer pairs COX2F/COX2R (631 bp) and FM66/FM58 (613 bp) amplified the cox 2 region of the host, Py. yezoensis. The sequence of the amplicons had $100 \%$ similarity with the cox2 sequence of Py. yezoensis (JQ736809; each $581 \mathrm{bp}$ and $573 \mathrm{bp}$ ).

\section{DISCUSSION}

The re-inoculation test successfully confirmed that the isolated P. chondricola causes pathogenesis in Py. yezoensis. The infection by $P$. chondricola caused cell death in healthy blades of Py. yezoensis maintained under indoor culture. The infected blades of Py. yezoensis showed characteristics typical of red rot disease (Takahashi et al. 1977).

We previously isolated coxl and internal transcribed spacer (ITS) sequences from culture strains of $P$. chondricola and infected samples of Py. yezoensis collected from aquaculture farms (Lee et al. 2015). However, the ITS sequences failed to discriminate $P$. chondricola from $P$. porphyrae. In contrast, the coxl region successfully provided useful genetic information for species identification. It has been suggested that a recently identified oomycete DNA barcode (Choi et al. 2015) could be used with the cox2 region, serving as a partner DNA barcode, because of its efficiency for PCR and sufficient variation for species identification. The cox2 region from the culture strain of P. chondricola is identical to that from the infected blade of Py. yezoensis.

The cox2 region has been used for molecular taxonomic studies of oomycetes (Hudspeth et al. 2000, Villa et al. 2006, Senda et al. 2009), and effective primer combinations were also developed. In these studies, most of the DNA samples were extracted from Pythium culture strains, and not from environmental samples such as infected Pyropia blades from aquaculture farms. Therefore, in the case of DNA analysis for host species of pathogens, the primer pair used to amplify the cox 2 region should be verified to specify the target pathogen species.
In this study, we assessed the efficacy of universal primers of the cox2 region for oomycetes to isolate the cox 2 region from the infected blades of Py. yezoensis. However, we were unable to acquire the Pythium cox 2 sequence. Furthermore, the universal primers did not show specificity for Pythium species, since this primer pair also amplified the cox2 region of the host Py. yezoensis. Therefore, cox2 primers that are appropriate for broad taxonomic groups of oomycetes might fail to detect the presence of Pythium species in the infected blades of Py. yezoensis.

We developed a new cox 2 primer set that exhibited specificity for Pythium species, thereby enabling us to isolate the Pythium cox2 sequence from host samples showing red rot disease. The primer pair (cox2-PACP-F1/ cox2-PACP-R1) developed in this study could successfully amplify the Pythium cox2 sequence with high efficiency and specificity.

For the Py. yezoensis blades collected from Biando and Gaeyado (Gunsan), a universal primer pair showed the non-specific band of Py. yezoensis. Nevertheless, the cox2 primer pair developed in the present study successfully amplified the cox2 region of Pythium from the Biando sample. The sequencing results show that the cox 2 amplicons obtained using the universal primer pair exhibited the Py. yezoensis cox 2 sequence instead of a Pythium sequence. These results strongly suggest the specificity of this new cox2 primer pair.

To confirm $P$. chondricola as an algal pathogen, a reinoculation experiment performed in accordance with Koch's postulates is required. In addition, the DNA barcode method is needed to detect Pythium species from samples in various states (e.g., decaying host samples or environmental samples, such as seawater and sediment). Here, we examined the pathogenesis of $P$. chondricola through the re-inoculation test and a novel molecular marker with high efficiency and specificity for Pythium.

Several coxl sequences have been reported under the names of $P$. chondricola and $P$. porphyrae from Japan, Korea, The Netherlands, New Zealand, and the USA (Robideau et al. 2011, Lee et al. 2015, Diehl et al. 2017, Klochkova et al. 2017). The coxl sequences (HQ708542, HQ708543, KY124355) were identical to that of the type culture of P. chondricola (HQ708544, CBS 203.85). Moreover, three $\operatorname{cox} 1$ sequences showed high similarity: HQ708545 (1 bp difference, 679/680 [99\%]), KX527563 (2 bp, 576/578 [99\%]), and KY650705 (2 bp, 676/678 [99\%]). In contrast, the coxl sequence of the type culture of $P$. porphyrae (HQ708794; CBS369.79) showed a 7 bp difference (673/680, 99\%) from that of the type culture of P. chondricola (HQ708544). 
The reported Pythium species show a diverse range of host infection (P. chondricola from Chondrus crispus [red algae], Ulva lactuca [green algae], Zostera marina [flowering plants] in De Cock (1986)); as P. porphyrae (KX527563) on the embryonic roots of various higher plants (e.g., carrot, cucumber, lettuce, and rice) in the artificial infection test of Klochkova et al. (2017); as P. porphyrae (KY650705) on Porphyra and Pyropia species in Diehl et al. (2017); as P. porphyrae on Py. tenera / Py. yezoensis in Kim et al. (2014); and P. chondricola (KY124355) on Py. yezoensis in Lee et al. (2015, this study). Interestingly, this broad range of host infection was also reported from the original description of P. chondricola (De Cock 1986).

Diehl et al. (2017) recently treated $P$. chondricola as a heterotypic synonym of $P$. porphyrae based on the identical ITS region and the high sequence similarity of the coxl region in the two species. However, the close genetic similarity among Pythium species has previously been reported from molecular taxonomic and DNA barcoding studies on the genus Pythium (Lévesque and De Cock 2004, Robideau et al. 2011). On the basis of the phylogenetic analyses of intra/interspecific variations, Robideau et al. (2011) treated P. chondricola as an independent species separate from $P$. porphyrae. Moreover, they proposed that the coxl region could be used as a molecular marker to discriminate between P. chondricola and P. porphyrae.

Of course, taxonomic re-examination will need to be conducted to clarify the taxonomic relationship among three allied Pythium species (P. adhaerens, P. chondricola, and $P$. porphyrae). However, for that purpose, more samples, including type cultures and more DNA sequences, should be examined. Therefore, for further studies, the distinctive genetic features of Korean $P$. chondricola should be conserved as an independent taxonomic entity apart from P. porphyrae.

The recent findings regarding a novel algal pathogen of Pyropia species causing red rot disease could suggest the cryptic biodiversity of oomycetes pathogens (Mo et al. 2016). Moreover, Park et al. (2003) investigated the genetic variation among Korean and Japanese isolates of P. porphyrae using random amplified polymorphic DNA and detected interesting genetic heterogeneity among Korean isolates. These results also support the possibility of intra/interspecific genetic diversity among Korean $P y$ thium species and the existence of P. chondricola as an independent species. Therefore, this research is expected to provide an accurate and reliable method for monitoring the distribution and infection pattern of $P$. chondricola / $P$. porphyrae in Pyropia aquaculture farms.

\section{ACKNOWLEDGEMENTS}

This study was supported by the National Institute of Fisheries Science (R2017067).

\section{REFERENCES}

Arasaki, S. 1947. Studies on the rot of Porphyra tenera by Pythium. Nippon Suisan Gakkaishi 13:74-90.

Arasaki, S., Akino, K. \& Tomiyama, T. 1968. A comparison of some physiological aspects in a marine Pythium on the host and on the artificial medium. Bull. Misaki Mar. Biol. Inst. Kyoto Univ. 12:203-206.

Blouin, N. A., Brodie, J. A., Grossman, A. C., Xu, P. \& Brawley, S. H. 2011. Porphyra: a marine crop shaped by stress. Trends Plant Sci. 16:29-37.

Choi, Y. -J., Beakes, G., Glockling, S., Kruse, J., Nam, B., Nigrelli, L., Ploch, S., Shin, H. -D., Shivas, R. G., Telle, S., Voglmayr, H. \& Thines, M. 2015. Towards a universal barcode of oomycetes: a comparison of the cox 1 and cox 2 loci. Mol. Ecol. Resour. 15:1275-1288.

De Cock, A. W. A. M. 1986. Marine Pythiaceae from decaying seaweeds in the Netherlands. Mycotaxon 25:101-110.

Diehl, N., Kim, G. H. \& Zuccarello, G. C. 2017. A pathogen of New Zealand Pyropia plicata (Bangiales, Rhodophyta), Pythium porphyrae (Oomycota). Algae 32:29-39.

Hudspeth, D. S. S., Nadler, S. A. \& Hudspeth, M. E. S. 2000. A COX2 molecular phylogeny of the Peronosporomycetes. Mycologia 92:674-684.

Kawamura, Y., Yokoo, K., Tojo, M. \& Hishiike, M. 2005. Distribution of Pythium porphyrae, the causal agent of red rot disease of Porphyrae spp., in the Ariake Sea, Japan. Plant Dis. 89:1041-1047.

Kim, G. H., Moon, K. -H., Kim, J. -Y., Shim, J. \& Klochkova, T. A. 2014. A revaluation of algal diseases in Korean Pyropia (Porphyra) sea farms and their economic impact. Algae 29:249-265.

Klochkova, T. A., Jung, S. \& Kim, G. H. 2017. Host range and salinity tolerance of Pythium porphyrae may indicate its terrestrial origin. J. Appl. Phycol. 29:371-379.

Lee, S. J., Hwang, M. S., Park, M. A., Baek, J. M., Ha, D. -S., Lee, J. -E. \& Lee, S. -R. 2015. Molecular identification of the algal pathogen Pythium chondricola (Oomycetes) from Pyropia yezoensis (Rhodophyta) using ITS and cox1 markers. Algae 30:217-222.

Lévesque, C. A. \& De Cock, A. W. A. M. 2004. Molecular phylogeny and taxonomy of the genus Pythium. Mycol. Res. 108:1363-1383.

Liu, Y. -M., Ma, J. -H. \&Wen, Q. 2012. Simultaneous infection 
by red rot and olpidiops disease in laver Porphyra haitanensis. J. Dalian Ocean Univ. 27:546-550.

Mo, Z., Li, S., Kong, F., Tang, X. \& Mao, Y. 2016. Characterization of a novel fungal disease that infects the gametophyte of Pyropia yezoensis (Bangiales, Rhodophyta). J. Appl. Phycol. 28:395-404.

Park, C. S., Kakinuma, M. \& Amano, H. 2006. Forecasting infections of the red rot disease on Porphyra yezoensis Ueda (Rhodophyta) cultivation farms. J. Appl. Phycol. 18:295-299.

Park, C. S., Kakinuma, M., Sakaguchi, K. \& Amano, H. 2003. Genetic variation detected with random amplified polymorphic DNA markers among isolates of the red rot disease fungus Pythium porphyrae isolated from Porphyra yezoensis from Korea and Japan. Fish. Sci. 69:361-368.

Robideau, G. P., De Cock, A. W. A. M., Coffey, M. D., Voglmayr, H., Brouwer, H., Bala, K., Chitty, D. W., Désaulniers, N., Eggertson, Q. A., Gachon, C. M. M., Hu, C. -H., Küpper, F. C., Rintoul, T. L., Sarhan, E., Verstappen, E. C. P., Zhang,
Y., Bonants, P. J. M., Ristaino, J. B. \& Lévesque, C. A. 2011. DNA barcoding of oomycetes with cytochrome $c$ oxidase subunit I and internal transcribed spacer. Mol. Ecol. Resour. 11:1002-1011.

Seifert, K. A. 2009. Progress towards DNA barcoding of fungi. Mol. Ecol. Resour. 9:83-89.

Senda, M., Kageyama, K., Suga, H. \& Lévesque, C. A. 2009. Two new species of Pythium, P. senticosum and $P$. takayamanum, isolated from cool-temperate forest soil in Japan. Mycologia 101:439-448.

Takahashi, M., Ichitani, T. \& Sasaki, M. 1977. Pythium porphyrae Takahashi et Sasaki, sp. nov. causing red rot of marine red algae Porphyra spp. Trans. Mycol. Soc. Jpn. 18:279-285.

Villa, N. O., Kageyama, K., Asano, T. \& Suga, H. 2006. Phylogenetic relationships of Pythium and Phytophthora species based on ITS rDNA, cytochrome oxidase II and $\beta$-tubulin gene sequences. Mycologia 98:410-422. 